\title{
Barriers to Access in Pediatric Living-Donor Liver Transplantation
}

Douglas B. Mogul ${ }^{1}$, Joy Lee ${ }^{2,3}$, Tanjala S. Purnell ${ }^{4,5}$, Allan B. Massie ${ }^{4,5}$, Tanveen Ishaque ${ }^{4}$, Dorry L. Segev ${ }^{4,5}$, John F.P. Bridges ${ }^{6}$

Corresponding author:

Douglas B. Mogul MD MPH

Assistant Professor of Pediatrics

Johns Hopkins University School of Medicine

600 N Wolfe Street, CMSC 2-117

Baltimore, MD 21287

tel: $410-955-8769$

dmogul1@jhmi.edu

${ }^{1}$ Department of Pediatrics, Johns Hopkins University School of Medicine, Baltimore, MD

${ }^{2}$ Department of Internal Medicine, Indiana University School of Medicine, Indianapolis, IN

${ }^{3}$ Center for Health Services Research, Regenstrief Institute, Indianapolis, IN

${ }^{4}$ Department of Surgery, Johns Hopkins University School of Medicine, Baltimore, MD

${ }^{5}$ Department of Epidemiology, Johns Hopkins School of Public Health, Baltimore, MD

${ }^{6}$ Department of Surgery, Ohio State University, Columbus, $\mathrm{OH}$

keywords: pediatric, living-donor, liver, barriers, access

\section{Financial support}

Dr. Mogul is supported by grant number 5K08HS023876 from the Agency for Healthcare Research and Quality (AHRQ). Dr. Purnell is supported by grant number K01HS024600 from AHRQ. Dr. Massie is supported by

This is the author's manuscript of the article published in final edited form as:

Mogul, D. B., Lee, J., Purnell, T. S., Massie, A. B., Ishaque, T., Segev, D. L., \& Bridges, J. F. P. (2019). Barriers to access in pediatric living-donor liver transplantation. Pediatric Transplantation, 23(6), e13513. https://doi.org/10.1111/petr.13513 
grant number K01DK101677 from the National Institute of Diabetes and Digestive and Kidney Diseases

(NIDDK). Dr. Segev is supported by grant number K24DK101828 from the NIDDK.

\section{Contribution statement:}

DM: all aspects of the manuscript including design, analysis and writing

$\mathrm{JL}$ and TP: design and implementation of the study, critical review of the manuscript.

$\mathrm{AB}$ and $\mathrm{TI}$ : analysis and critical feedback of manuscript

DS: critical feedback of manuscript

JB: all aspects of the manuscript including design, analysis and writing

Abbreviations: living-donor liver transplant (LDLT), whole liver transplant (WLT)

\section{Conflict of interest}

None 


\section{ABSTRACT}

Children receiving a living-donor liver transplant (LDLT) have superior post-transplant outcomes but this procedure is only used for $10 \%$ of transplant recipients. Better understanding about barriers toward LDLT and the sociodemographic characteristics that influence these underlying mechanisms would help to inform strategies to increase its use. We conducted an online, anonymous survey of parents/caregivers for children awaiting, or have received, a liver transplant regarding their knowledge and attitudes about LDLT. The survey was completed by 217 respondents. While $97 \%$ of respondents understood an individual could donate a portion of their liver, only $72 \%$ knew the steps in evaluation, and $69 \%$ understood the donor surgery was covered by the recipient's insurance. Individuals with public insurance were less likely than those with private insurance to know the steps for LDLT evaluation (44\% vs $82 \% ; P<0.001$ ). Respondents with public insurance were less likely to know someone that had been a living donor (44\% vs $56 \% ; P=0.005)$ as were individuals without a college degree (64\% vs $85 \% ; P=0.007)$. Nearly all respondents generally trusted their healthcare team. Among respondents, $82 \%$ believed they were well-informed about LDLT but individuals with public insurance were significantly less likely to feel well-informed ( $67 \%$ vs $87 \% ; P=0.03)$ and to understand how donor surgery might impact donor work/time-off (44\% vs $81 \% ; P=0.001)$. Substantial gaps exist in parental understanding about LDLT, including its evaluation, potential benefits, and complications. Greater emphasis on addressing these barriers, especially to individuals with fewer resources, will be helpful to expand the use of LDLT. 


\section{INTRODUCTION}

Liver transplantation is the definitive cure for children with end-stage liver disease and has provided life-saving therapy to more than 5,000 children in the United States over the past decade. ${ }^{1}$ Outcomes following transplant are excellent with an overall 1-year patient survival of $93 \%$ and 1 -year graft survival of $89 \% .{ }^{2}$ Living-donor liver transplantation (LDLT), although more surgically complex than whole liver transplantation (WLT), has superior outcomes with a 96\% 1-year patient survival and 94\% 1-year graft survival. This finding is particularly exciting because LDLT provides an opportunity to transplant children before they develop substantial pre-transplant morbidity and to mitigate the risk of dying on the waitlist. Despite these benefits, only $10 \%$ of pediatric liver transplant candidates are transplanted using a living donor and its use has been stable over recent years. ${ }^{3-5}$

Several theoretical frameworks exist that describe how access to care is influenced by individual, socioorganization, and geographic factors, and these underlying mechanisms are evident in access to living-donor transplantation. ${ }^{6,7}$ Much of what is known about barriers in access to living-donor transplantation has been observed within the context of adult kidney transplantation. First, studies of adult kidney transplant patients suggest that candidates may lack information about living donation including benefits to the recipient and the potential risk/safety for the donor. ${ }^{8-11}$ Second, evidence exists from this population that some patients and potential donors may have general mistrust of the medical community and therefore seek to avoid an additional surgery. ${ }^{12}$ Third, candidates and their families may have, or perceive they have, limited social networks or individuals that they feel comfortable approaching about living donation. ${ }^{13-15}$ Fourth, there may be social or financial limitations on an individual's ability to pursue living donation. ${ }^{16-19}$ And fifth, transplant teams may variably support the option of living donation for their patients, such that the option is not offered at their center or even region. Socioeconomic characteristics have also been shown in liver transplantation to influence access of LDLT and further promote health disparities in both adult and pediatric candidates. ${ }^{20-24}$ For example, children on public insurance are half as likely to use a living donor as children with private insurance, and African-American children are half as likely as Caucasian children to be transplanted with a living donor.

To better understand barriers toward access of LDLT for pediatric candidates, and to explore how these barriers may be influenced by sociodemographic characteristics, we surveyed online Facebook communities of 
parents and caregivers for children who are awaiting, or have received, a liver transplant. This information could then help to identify potential strategies to increase the use of LDLT for pediatric candidates awaiting transplantation.

\section{METHODS}

\section{Study Population}

The study population was a convenience sample of parents of children ( $<18$ years) who are currently being evaluated for a liver transplant, waitlisted for transplant, or recipients of a liver transplant. Parents who were $>18$ years of age and able to speak English were eligible to participate.

\section{Recruitment Strategy}

Respondents were recruited over Facebook using several mechanisms from February to April, 2018. First, respondents were recruited through Liver Space, a Facebook-integrated "app" that is free and available on the Apple and Android stores and that has been described elsewhere. ${ }^{25}$ Briefly, Liver Space provides users with several functions such as the ability to receive the latest news of interest to the user, ask-an-expert questions, locate other members of the community to arrange meetups, and track laboratory results. At the beginning of the study period, Liver Space had 450 users including 171 (38\%) parent/caregivers and 230 (51\%) patients, and $105(23 \%)$ individuals were listed as transplant recipients. Second, respondents were recruited through the Liver Space page on Facebook, which had 982 followers at the start of the recruitment period. Third, two paid Facebook campaigns directed toward adults with interest in liver issues were promoted in a campaign that had a combined reach of 2,099 people. And finally, Facebook posts were shared over five large groups, each with greater than 1,000 members and are focused on pediatric liver disease or liver transplantation. Respondents were informed that participation was voluntary, and they would not be reimbursed for completing the study. The anonymous study was exempted by the Institutional Review Board of the Johns Hopkins University School of Medicine.

\section{Instrument}

The survey was developed by study team members including individuals with expertise in transplant 
hepatology, clinical research, survey development, health services research, epidemiology, and health disparities research. The anonymous, quantitative survey consisted of 44 questions including 25 questions addressing knowledge and attitudes about transplantation that used a 5-point Likert scale (i.e., "strongly agree," "somewhat agree," "neutral," "somewhat disagree," and "strongly disagree"). Questions assessed the following potential barriers: (1) knowledge about the living donor evaluation process, including an understanding that a family member or friend can donate a part of their liver, the steps for evaluation, and that the cost of donor surgery and follow-up is covered by recipient's insurance; (2) knowledge about outcomes following living donation as compared to WLT; (3) size and nature of an individual's social network, including whether they knew someone that been evaluated, or served, as a living donor; the number of people with whom they discuss health-related issues; and their perception of how it might affect relationships; (4) trust in the medical community, including whether they trust their doctor to do the right thing, typically agree with their doctor, and felt their questions were answered; and (5) their perception about provider communication as it relates to concerns about outcomes for the donor, outcomes for the recipient, and concerns about the burden associated with donation.

Respondents were also asked additional questions that further characterized their sociodemographic background including: (1) insurance status, i.e., public (exclusively Medicaid or public insurance connected to income) versus private or mixed public/private; (2) education level; (3) marital status, i.e., single versus married or living with partner; (4) employment status, i.e., fully employed, part-time employed, homemaker, other; (5) number of working adults in the house; and (6) race/ethnicity. Their technological "fluency" (i.e., frequency and use of digital devices) was also assessed. They survey was pilot tested for grammar and clarity by patients. The survey was created and distributed through Qualtrics (Provo, UT).

\section{Missing Data}

Among 217 eligible respondents, missingness from the survey occurred for the following demographic variables: sex $(n=56)$, race/ethnicity, marital status, employment, education, and number of working adults ( $n$ $=58)$. At least one missing demographic variable occurred in $85(39 \%)$ respondents. A missing indicator variable was created in order to test whether missingness affected responses to a random selection of 
questions from the domains. In all instances, missingness was not associated with the response and subsequent analyses were therefore made only for individuals that had complete data without imputation of missing data.

\section{Statistical Analysis}

Data were summarized using frequencies, percentages, medians, and interquartile ranges (IQR). Associations between categorical variables were tested using a Fisher's exact (when $n<5$ ) or chi-squared tests, whereas associations between ordinal variables used a Wilcoxon rank sum test. Questions using a 5-point Likert scale were ultimately dichotomized to compare the two affirmative responses (i.e., "strongly agree" and "somewhat agree") with the remaining three options (i.e., "strongly disagree," "somewhat disagree," and "neutral").

Statistical significance was assessed at the $\alpha=0.05$ confidence level. All analyses were performed using Stata 14.0/MP for Apple (College Station, TX).

\section{RESULTS}

\section{Study Population}

A total of 217 eligible individuals completed the survey including $27(12 \%)$ that were parents of children being evaluated or waitlisted for a liver transplant and $190(88 \%)$ that were parents of children that had received a transplant; 34 individuals were excluded because their child was neither being evaluated or waitlisted for transplant, nor had they received a transplant. There was no difference in the demographic characteristics of respondents of children that were evaluated/waitlisted compared to children that had already been transplanted (Table 1). Respondents were mostly female (93\%) with a median age of 38 (IQR: $34-45)$ years and the median age of the child was $5(2-11)$ years. All respondents were residents of the United States. The insurance status of participants included $64 \%$ with only private insurance, $12 \%$ with only Medicaid, and $24 \%$ with a combination of public and private payers. The majority of participants were married or living with a partner $(86 \%)$. Half of respondents were fully employed and $61 \%$ were from families that had $>1$ working adult. A college degree was obtained by $77 \%$ of participants. Among respondents, $87 \%$ identified as white nonHispanic, 4\% Asian, 3\% African American, 3\% Hispanic, and 4\% mixed/other. The respondents were technologically fluent, with $94 \%$ owning multiple digital devices (i.e., smartphones, tablets, computers) and 
$99 \%$ using these devices for at least 1 hour each day. Their health status was rated as at least "good" by $91 \%$ of respondents.

\section{Knowledge of Living-Donor Evaluation}

When asked about their understanding of living donation, $97 \%$ were aware that LDLT was an option and $90 \%$ knew who to ask about the process, but only $72 \%$ were knowledgeable about the actual steps and $69 \%$ were aware that costs were covered by the recipient's insurance (Table 2). Awareness that LDLT was an option was similar for parents of children that are currently being evaluated or waitlisted compared to transplant recipients ( $91 \%$ vs $98 \% ; P=0.1)$, but the former were less likely to know who to ask ( $65 \%$ vs $93 \% ; P<0.001)$, know the steps for evaluation ( $44 \%$ vs $77 \% ; P=0.001$ ), or know that the cost of the procedure was covered by the recipient's insurance $(43 \%$ vs $77 \% ; P=0.004)$.

Insurance status (exclusively public vs private/mixed) was not associated with general awareness that LDLT is an option ( $100 \%$ vs $98 \% ; P=0.6)$, knowledge about which provider to ask about the evaluation ( $89 \%$ vs $95 \%$; $P=0.3)$, or knowledge that the donor surgery is covered by the recipient's insurance (61\% vs $78 \% ; P=0.1)$, but respondents with public insurance were nearly half as likely to know the actual steps for LDLT evaluation (44\% vs $82 \% ; P<0.001$ ). Similarly, single parents were equally likely to be aware that LDLT is an option (96\% vs $99 \% ; P=0.3)$ and which provider to ask about the evaluation ( $92 \%$ vs $100 \% ; P=0.2)$, but significantly less likely to know the specific steps for the evaluation ( $57 \%$ vs $81 \% ; P=0.01)$ or that the cost of the donor surgery was covered by the recipient's insurance $(52 \%$ vs $76 \% ; P=0.02)$. Employment status (i.e., full-time employment vs non-full-time employment), number of working adults in the house, education level, and race/ethnicity were not associated with knowledge about LDLT, which provider to ask about the evaluation, the steps for evaluation, or insurance coverage for the procedure.

\section{Outcomes Following Living Donation}

Only $38 \%$ of respondents correctly understood that outcomes following living donation are better than deceased donation, whereas $46 \%$ thought the outcomes were the same, $17 \%$ thought living donation was worse, and $9 \%$ of respondents had no opinion about relative outcomes for each surgery. Understanding about 
outcomes following LDLT was not associated with whether the respondent's child was currently being evaluated or waitlisted or had been transplanted $(P=0.3)$. Single parents were more likely than parents that were married or living with a partner to believe outcomes were worse following living donation $(22 \%$ vs $4 \% ; P=$ 0.03); otherwise, insurance, educational, employment, or race/ethnicity were not associated with knowledge about outcomes following LDLT compared to deceased donation.

\section{Social Network}

Over $90 \%$ of respondents indicated they had at least 2 individuals with whom they were comfortable asking to be a living donor. The number of people with whom respondents would be comfortable asking to consider living donation for their child was independent of a respondent's sociodemographic background. Likewise, whereas $26 \%$ of respondents believed that asking a friend or family member about potentially being a donor may cause stress in the relationship, this belief was independent of sociodemographic variables. Respondents with public insurance were less likely than those with private insurance to actually know someone who had been a living donor ( $44 \%$ vs $56 \% ; P=0.005)$ as were individuals without a college degree compared to those with a college degree (64\% vs $85 \% ; P=0.007)$. Employment status, number of working adults in household, or race/ethnicity were not associated with knowing someone who had been a living donor.

\section{Trust in Medical Community}

Although some respondents were told they were ineligible to donate (16\%), among parents that perceived they could be considered potential LDLT donors $(n=157)$, $97 \%$ were comfortable with the idea. Over $90 \%$ of respondents indicated that they liked their doctor, trusted their doctor to do the right thing for their child, generally agreed with the treatment plan, and felt their doctor answered all their questions (Table 3). Respondents with public insurance were equally likely to trust their child's doctor, agree with the medical plan, and feel their questions were answered but were less likely to like their doctor than individuals with private insurance ( $83 \%$ vs $97 \% ; P=0.04$ ). Neither parental education level nor marital status were associated with trust in the medical community. However, while having $\leq 1$ working adult in the household was not associated with trust in the medical community, fully-employed parents were more likely to trust their doctor ( $99 \%$ vs $91 \%$; 
$P=0.03)$ and feel their questions were answered (99\% vs $89 \% ; P=0.02)$. Race/ethnicity was not associated with any aspect of trust in the medical community.

\section{Provider Communication}

Overall, $82 \%$ of respondents believed they were generally well-informed by their healthcare team about LDLT (Table 4). Parents of children who are currently undergoing evaluation or waitlisted were less likely than children who have been transplanted to feel well-informed (43\% vs $87 \% ; P<0.001)$. Individuals with public insurance were less likely to feel well-informed about LDLT $(67 \%$ vs $87 \% ; P=0.03)$ whereas this perception did not vary by marital status, education, employment, or race/ethnicity. Only $86 \%$ of respondents believed they were well-informed about complications to the recipient and $76 \%$ believed they were well-informed about potential complications to the donor, and this was independent of sociodemographic background.

With respect to feeling well-informed about the impact of living donation on the donor's work (i.e., time off), $75 \%$ felt they were adequately informed, but this was lower in individuals on public insurance (44\% vs $81 \% ; P$ $=0.001)$. Otherwise, education, employment, marital status or race were not associated with whether respondents considered themselves fully informed about the impact of LDLT on donor work.

\section{DISCUSSION}

There is tremendous need to better understand barriers toward access of LDLT for pediatric candidates given that outcomes following LDLT are better than deceased donation and that the procedure offers opportunities to reduce waitlist morbidity and mortality. Among our cohort of largely healthy parents, a number of important observations can be identified regarding barriers toward LDLT and factors that potentiate these barriers. First, while nearly all parents were broadly aware of living donation as an option, substantially fewer were knowledgeable about the process including which providers to ask, what are the steps, and how the procedure is covered by insurance. Parents with public insurance or from single-parent households were less likely to understand the process. Second, $18 \%$ of parents felt they were generally poorly informed by their providers about LDLT and $24 \%$ felt they were specifically not well-informed about risk to the donor, or the impact on the donor's work. Third, only approximately one-third of parents correctly knew that outcomes following LDLT were 
actually better than deceased donation. Fourth, while many of the respondents were generally comfortable asking several people to be a living donor, one quarter believed this may cause stress in a relationship. And fifth, low use of living donation cannot be explained by a lack of trust in the medical community.

While most respondents were aware that living donation is an option, it is concerning that a large percentage of parents do not know basic aspects of the process such as which provider to ask, what are the relative outcomes compared to deceased donation, and what are complications for the donor and recipient. One explanation may be that many respondents are receiving care for their children at centers where LDLT is not performed and that less information may be provided to families at these centers. Presently, LDLT is only offered in approximately one-quarter of programs. ${ }^{26}$ We initially sought to determine the impact of availability of LDLT at the respondent's center on their knowledge of LDLT but this information was not properly captured by the survey platform and could not be analyzed. Nonetheless, the unique requirement by the Center for Medicare Services, which has some regulatory oversight for the transplantation system in the United States, that all people undergoing evaluation for transplantation be presented with national statistics on patient and graft survival for both deceased and living donation speaks to the importance that all individuals be made aware of these outcomes. ${ }^{27}$ Therefore, a lack of availability of LDLT at a specific center is not a sufficient explanation to justify a lack of understanding that living donation has superior (or at least equivalent) outcomes to deceased donation.

It is worth noting that people who have completed the transplant process felt better informed $(87 \%)$ than those that were still being evaluated or waitlisted (43\%). This may reflect an increase in certainty about their knowledge of several aspects of transplantation, including LDLT, once the transplant is complete. Purnell et al., note that different barriers exist throughout the transplant process, from referral to evaluation to being waitlisted to receiving a transplant, and that individuals who are transplanted represent a subset of individuals that were able to overcome these barriers. ${ }^{28}$

The association between specific sociodemographic characteristics and reduced use of LDLT have been reported elsewhere. ${ }^{29}$ In a large registry study of children with biliary atresia, individuals with public insurance 
had significantly lower rates of LDLT, which is not surprising given that public insurance can serve as a proxy for lower income and fewer resources, alongside the observation that living donation is associated with increased financial burden for donors. ${ }^{16,20}$ Here, we explore in greater detail other potential mechanisms that may act as barriers, including that this population is less likely to know the steps for living donor evaluation, to feel generally well-informed about LDLT, to understand how LDLT may impact their work and other responsibilities, and to know someone that had gone through the process. Lack of adequate information is also evident with single parents and this finding has been reported from adult studies as well. ${ }^{30}$

Sociodemographic variables such as insurance status likely mediate the relationship between race/ethnicity and access to living donation, and substantial research exists in the adult liver and kidney literature as well as pediatric kidney literature that may help elucidate these barriers. ${ }^{31}$ For example, studies have identified that African Americans are more likely to be concerned about the procedure's impact on personal relationships and concerns about finances, while distrust of the medical community and decreased medical literacy may contribute to lower use of living donation as well. ${ }^{8,32-34}$ Among African Americans, these barriers have been shown to lead to fewer inquiries by potential living donors per candidate. ${ }^{35}$ Unfortunately, one major limitation of our study was the low response rate of non-Caucasian individuals in our sample, making it impossible to understand any potential impact of race/ethnicity on the use of living donation in pediatric liver candidates; although Facebook is used by all racial/ethnic groups equally at around $75 \%$, it has been reported that African Americans may be less willing to share health information online compared with other groups. ${ }^{36-38}$ Nonetheless, given that our sample was comprised of predominantly Caucasian women that may be more engaged in their health or healthcare research than the general population of parents of children awaiting or having received a liver transplant, our findings should be interpreted with caution.

Several encouraging observations should be noted. First, individuals generally trusted their doctors and believed that their healthcare team would do the right thing for the patient. Second, individuals generally reported strong social networks and willingness to discuss living donation with other people. At the same time, one limitation of our study is that it was distributed over social media, allowing for the possibility that our sample is not broadly representative of the population of parents of children with end-stage liver disease. 
Rather, our cohort may represent a sample that is both more trusting of healthcare providers/scientists such

that they are willing to complete a survey, and that they are more open to sharing their health experiences and struggles.

These findings highlight the need for programs to provide additional education to the community, through public forums, social media, and other mechanisms to provide comprehensive information to all individuals. ${ }^{39}$ Although we didn't measure health literacy directly, education level has been shown to correlate with health literacy in the transplant population. ${ }^{40,41}$ Navigating the transplant process, from referral through surgery, has been shown to depend heavily on education, and this need is especially true for living donor transplantation. ${ }^{42,43}$ Fortunately, evidence exists from clinical trials of adult kidney transplant candidates that educational programs can lead to higher knowledge and fewer concerns with living donation as well as an increase the number of donor inquiries. ${ }^{44}$ Application of education programs regarding LDLT to the pediatric liver community can therefore be reasonably expected to increase its use, further decrease waitlist morbidity and mortality, and lead to better long-term survival.

\section{ACKNOWLEDGEMENTS}

The authors wish to acknowledge Tristin Bates and Martin Maren for their help with distribution of the survey over Facebook.

\section{REFERENCES}

1. Data - OPTN. https://optn.transplant.hrsa.gov/data. Accessed July 23, 2018.

2. Mogul DB, Luo X, Bowring MG, et al. Fifteen-Year Trends in Pediatric Liver Transplants: Split, Whole Deceased, and Living Donor Grafts. J Pediatr. January 2018. doi:10.1016/j.jpeds.2017.11.015

3. Kim WR, Stock PG, Smith JM, et al. OPTN/SRTR 2011 Annual Data Report: liver. Am J Transplant Off J Am Soc Transplant Am Soc Transpl Surg. 2013;13 Suppl 1:73-102. doi:10.1111/ajt.12021

4. Kim WR, Lake JR, Smith JM, et al. OPTN/SRTR 2016 Annual Data Report: Liver. Am J Transplant Off J Am Soc Transplant Am Soc Transpl Surg. 2018;18 Suppl 1:172-253. doi:10.1111/ajt.14559

5. Mogul DB, Luo X, Bowring MG, et al. Fifteen-Year Trends in Pediatric Liver Transplants: Split, Whole Deceased, and Living Donor Grafts. J Pediatr. January 2018. doi:10.1016/j.jpeds.2017.11.015

6. PromotingHealthyBehavior_Eng.pdf.

https://assets.prb.org/pdf05/PromotingHealthyBehavior_Eng.pdf?q=promoting. Accessed August 28, 
2018.

7. Aday LA, Andersen R. A framework for the study of access to medical care. Health Serv Res. 1974;9(3):208-220.

8. Purnell TS, Hall YN, Boulware LE. Understanding and overcoming barriers to living kidney donation among racial and ethnic minorities in the United States. Adv Chronic Kidney Dis. 2012;19(4):244-251.

doi:10.1053/j.ackd.2012.01.008

9. Segev DL, Powe NR, Troll MU, Wang N-Y, Montgomery RA, Boulware LE. Willingness of the United States general public to participate in kidney paired donation. Clin Transplant. 2012;26(5):714-721.

doi:10.1111/j.1399-0012.2012.01596.x

10. Sieverdes JC, Nemeth LS, Magwood GS, et al. African American kidney transplant patients' perspectives on challenges in the living donation process. Prog Transplant Aliso Viejo Calif. 2015;25(2):164-175. doi:10.7182/pit2015852

11. Waterman AD, Peipert JD, Hyland SS, McCabe MS, Schenk EA, Liu J. Modifiable patient characteristics and racial disparities in evaluation completion and living donor transplant. Clin J Am Soc Nephrol CJASN. 2013;8(6):995-1002. doi:10.2215/CJN.08880812

12. Wachterman MW, McCarthy EP, Marcantonio ER, Ersek M. Mistrust, misperceptions, and miscommunication: a qualitative study of preferences about kidney transplantation among African Americans. Transplant Proc. 2015;47(2):240-246. doi:10.1016/j.transproceed.2015.01.016

13. Rodrigue JR, Cornell DL, Kaplan B, Howard RJ. Patients' willingness to talk to others about living kidney donation. Prog Transplant Aliso Viejo Calif. 2008;18(1):25-31.

14. Traino HM, West SM, Nonterah CW, Russell J, Yuen E. Communicating About Choices in Transplantation (COACH). Prog Transplant Aliso Viejo Calif. 2017;27(1):31-38. doi:10.1177/1526924816679844

15. Boulware LE, Meoni LA, Fink NE, et al. Preferences, knowledge, communication and patient-physician discussion of living kidney transplantation in African American families. Am J Transplant Off J Am Soc Transplant Am Soc Transpl Surg. 2005;5(6):1503-1512. doi:10.1111/j.1600-6143.2005.00860.x

16. DiMartini A, Dew MA, Liu Q, et al. Social and Financial Outcomes of Living Liver Donation: A Prospective Investigation Within the Adult-to-Adult Living Donor Liver Transplantation Cohort Study 2 (A2ALL-2). Am J Transplant Off J Am Soc Transplant Am Soc Transpl Surg. 2017;17(4):1081-1096. doi:10.1111/ajt.14055

17. Habbous S, Sarma S, Barnieh LJ, et al. Healthcare Costs for the Evaluation, Surgery, and Follow-Up Care of Living Kidney Donors. Transplantation. 2018;102(8):1367-1374. doi:10.1097/TP.0000000000002222

18. Dew MA, Jacobs CL. Psychosocial and socioeconomic issues facing the living kidney donor. Adv Chronic Kidney Dis. 2012;19(4):237-243. doi:10.1053/j.ackd.2012.04.006

19. Rodrigue JR, Kazley AS, Mandelbrot DA, et al. Living Donor Kidney Transplantation: Overcoming Disparities in Live Kidney Donation in the US--Recommendations from a Consensus Conference. Clin J Am Soc Nephrol CJASN. 2015;10(9):1687-1695. doi:10.2215/CJN.00700115

20. Arnon R, Annunziato RA, Willis A, et al. Liver transplantation for children with biliary atresia in the pediatric end-stage liver disease era: the role of insurance status. Liver Transplant Off Publ Am Assoc Study Liver Dis Int Liver Transplant Soc. 2013;19(5):543-550. doi:10.1002/It.23607

21. Mogul DB, Luo X, Chow EK, et al. Impact of Race and Ethnicity on Outcomes for Children Waitlisted for Pediatric Liver Transplantation. J Pediatr Gastroenterol Nutr. 2018;66(3):436-441.

doi:10.1097/MPG.0000000000001793 
22. Thammana RV, Knechtle SJ, Romero R, Heffron TG, Daniels CT, Patzer RE. Racial and socioeconomic disparities in pediatric and young adult liver transplant outcomes. Liver Transplant Off Publ Am Assoc Study Liver Dis Int Liver Transplant Soc. 2014;20(1):100-115. doi:10.1002/lt.23769

23. Mathur AK, Schaubel DE, Gong Q, Guidinger MK, Merion RM. Racial and ethnic disparities in access to liver transplantation. Liver Transplant Off Publ Am Assoc Study Liver Dis Int Liver Transplant Soc. 2010;16(9):1033-1040. doi:10.1002/It.22108

24. Mathur AK, Ashby VB, Fuller DS, et al. Variation in access to the liver transplant waiting list in the United States. Transplantation. 2014;98(1):94-99. doi:10.1097/01.TP.0000443223.89831.85

25. Mogul DB, Henderson ML, Bridges JFP. Expanding the Facebook Platform to Engage and Educate Online Communities. Am J Gastroenterol. 2018;113(4):457-458. doi:10.1038/ajg.2017.450

26. Kim PTW, Testa G. Living donor liver transplantation in the USA. Hepatobiliary Surg Nutr. 2016;5(2):133140. doi:10.3978/j.issn.2304-3881.2015.06.01

27. DEPARTMENT OF HEALTH \& HUMAN SERVICES.pdf. https://www.cms.gov/Medicare/ProviderEnrollment-and-Certification/SurveyCertificationGenInfo/downloads/SCLetter08-25.pdf. Accessed July 26, 2018.

28. Purnell TS, Hall YN, Boulware LE. Understanding and overcoming barriers to living kidney donation among racial and ethnic minorities in the United States. Adv Chronic Kidney Dis. 2012;19(4):244-251.

doi:10.1053/j.ackd.2012.01.008

29. Ross K, Patzer RE, Goldberg DS, Lynch RJ. Sociodemographic Determinants of Waitlist and Posttransplant Survival Among End-Stage Liver Disease Patients. Am J Transplant Off J Am Soc Transplant Am Soc Transpl Surg. 2017;17(11):2879-2889. doi:10.1111/ajt.14421

30. Doyle A, Rabie RN, Mokhtari A, et al. Recipient factors associated with having a potential living donor for liver transplantation. Liver Transplant Off Publ Am Assoc Study Liver Dis Int Liver Transplant Soc. 2015;21(7):897-903. doi:10.1002/It.24148

31. Purnell TS, Luo X, Cooper LA, et al. Association of Race and Ethnicity With Live Donor Kidney Transplantation in the United States From 1995 to 2014. JAMA. 2018;319(1):49-61. doi:10.1001/jama.2017.19152

32. Amaral S, Patzer R. Disparities, race/ethnicity and access to pediatric kidney transplantation. Curr Opin Nephrol Hypertens. 2013;22(3):336-343. doi:10.1097/MNH.0b013e32835fe55b

33. Shilling LM, Norman ML, Chavin KD, et al. Healthcare professionals' perceptions of the barriers to living donor kidney transplantation among African Americans. J Natl Med Assoc. 2006;98(6):834-840.

34. Gore JL, Danovitch GM, Litwin MS, Pham P-TT, Singer JS. Disparities in the utilization of live donor renal transplantation. Am J Transplant Off J Am Soc Transplant Am Soc Transpl Surg. 2009;9(5):1124-1133. doi:10.1111/j.1600-6143.2009.02620.x

35. Nobel YR, Forde KA, Wood L, et al. Racial and ethnic disparities in access to and utilization of living donor liver transplants. Liver Transplant Off Publ Am Assoc Study Liver Dis Int Liver Transplant Soc. 2015;21(7):904-913. doi:10.1002/lt.24147

36. NW 1615 L. St, Washington S 800, Inquiries D 20036 U-419-4300 | M-419-4372 | M. Social Media Fact Sheet. Pew Res Cent Internet Sci Tech. February 2018. http://www.pewinternet.org/fact-sheet/socialmedia/. Accessed July 26, 2018.

37. PricewaterhouseCoopers. Social media "likes" healthcare: From marketing to social business. PwC. https://www.pwc.com/us/en/health-industries/health-research-institute/publications/health-care-social- 
media.html. Accessed July 26, 2018.

38. Mitchell SJ, Godoy L, Shabazz K, Horn IB. Internet and mobile technology use among urban African American parents: survey study of a clinical population. J Med Internet Res. 2014;16(1):e9.

doi:10.2196/jmir.2673

39. Melloul E, Raptis DA, Oberkofler CE, Dutkowski P, Lesurtel M, Clavien P-A. Donor information for living donor liver transplantation: where can comprehensive information be found? Liver Transplant Off Publ Am Assoc Study Liver Dis Int Liver Transplant Soc. 2012;18(8):892-900. doi:10.1002/lt.23442

40. Escobedo W, Weismuller P. Assessing health literacy in renal failure and kidney transplant patients. Prog Transplant Aliso Viejo Calif. 2013;23(1):47-54. doi:10.7182/pit2013473

41. Warsame F, Haugen CE, Ying $\mathrm{H}$, et al. Limited Health Literacy and Adverse Outcomes Among Kidney Transplant Candidates. Am J Transplant Off J Am Soc Transplant Am Soc Transpl Surg. July 2018. doi:10.1111/ajt.14994

42. Li T, Dokus MK, Kelly KN, et al. Survey of Living Organ Donors' Experience and Directions for Process Improvement. Prog Transplant Aliso Viejo Calif. 2017;27(3):232-239. doi:10.1177/1526924817715467

43. Kucirka LM, Purnell TS, Segev DL. Improving Access to Kidney Transplantation: Referral Is Not Enough. JAMA. 2015;314(6):565-567. doi:10.1001/jama.2015.8932

44. Rodrigue JR, Paek MJ, Egbuna O, et al. Making house calls increases living donor inquiries and evaluations for blacks on the kidney transplant waiting list. Transplantation. 2014;98(9):979-986. doi:10.1097/TP.0000000000000165 
Table 1: Demographic characteristics of survey respondents

\begin{tabular}{|c|c|c|c|c|}
\hline & All & Evaluated/Waitlisted & Transplanted & $P$ \\
\hline Female, n (\%) & $149(93)$ & $14(88)$ & $135(93)$ & 0.3 \\
\hline Parent age (years), median (IQR) & $38(34-45)$ & $36(31-42)$ & $38(34-45)$ & 0.2 \\
\hline Child age (years), median (IQR) & $5(2-11)$ & $4(1-6)$ & $5(2-11)$ & 0.2 \\
\hline \multicolumn{5}{|l|}{ Insurance, $\mathrm{n}(\%)$} \\
\hline public & $18(12)$ & $3(20)$ & $15(11)$ & 0.1 \\
\hline private & $93(64)$ & $6(40)$ & $87(66)$ & \\
\hline mixed & $35(24)$ & $6(40)$ & $29(22)$ & \\
\hline \multicolumn{5}{|l|}{ Marital status, n (\%) } \\
\hline single & $23(14)$ & $2(13)$ & $21(15)$ & 0.9 \\
\hline married/partner & $136(86)$ & $14(88)$ & $122(85)$ & \\
\hline \multicolumn{5}{|l|}{ Employment, n (\%) } \\
\hline full-time & $81(51)$ & $9(56)$ & $72(50)$ & 0.4 \\
\hline part-time & $21(13)$ & $3(19)$ & $18(13)$ & \\
\hline homemaker & $43(27)$ & $2(13)$ & $41(29)$ & \\
\hline other & $14(9)$ & $2(13)$ & $12(8)$ & \\
\hline \multicolumn{5}{|c|}{ Number of working adults in house, $\mathrm{n}(\%)$} \\
\hline$\leq 1$ & $62(39)$ & $5(31)$ & $57(40)$ & 0.5 \\
\hline$>1$ & $97(61)$ & $11(69)$ & $86(60)$ & \\
\hline \multicolumn{5}{|l|}{ Education, n (\%) } \\
\hline less than college degree & $36(23)$ & $5(31)$ & $31(22)$ & 0.4 \\
\hline college degree & $123(77)$ & $11(69)$ & $112(78)$ & \\
\hline \multicolumn{5}{|l|}{ Race/ethnicity, n (\%) } \\
\hline Caucasian non-Hispanic & $138(87)$ & $13(81)$ & $125(87)$ & 0.4 \\
\hline other & $21(13)$ & $3(19)$ & $18(13)$ & \\
\hline \multicolumn{5}{|l|}{ Device ownership, n (\%) } \\
\hline multiple & $149(94)$ & $14(88)$ & $135(94)$ & 0.3 \\
\hline single (smartphone or computer) & $10(6)$ & $2(13)$ & $8(6)$ & \\
\hline
\end{tabular}




\begin{tabular}{l|c|c|c|c} 
Access of internet $>1$ hour per day, $\mathrm{n}(\%)$ & $157(99 \%)$ & $16(100)$ & $141(99)$ & 0.9 \\
\hline $\begin{array}{l}\text { Health status (of respondent), } \mathrm{n}(\%) \\
\text { poor or fair }\end{array}$ & $15(9)$ & $0(0)$ & $15(11)$ & 0.4 \\
\hline good, very good or excellent & $143(91)$ & $16(100)$ & $127(89)$ &
\end{tabular}


Table 2: Knowledge about living donation and steps for evaluation

\begin{tabular}{|c|c|c|c|c|c|c|c|c|}
\hline & \multicolumn{2}{|c|}{$\begin{array}{l}\text { Family/friend } \\
\text { can donate }\end{array}$} & \multicolumn{2}{|c|}{$\begin{array}{l}\text { Which provider } \\
\text { to ask about } \\
\text { evaluation }\end{array}$} & \multicolumn{2}{|c|}{$\begin{array}{l}\text { Steps for } \\
\text { evaluation }\end{array}$} & \multicolumn{2}{|c|}{$\begin{array}{l}\text { Costs covered } \\
\text { by recipient } \\
\text { insurance }\end{array}$} \\
\hline & $\%$ & $P$ & $\%$ & $\boldsymbol{P}$ & $\%$ & $P$ & $\%$ & $\boldsymbol{P}$ \\
\hline Overall & 97 & -- & 90 & -- & 72 & -- & 69 & -- \\
\hline \multicolumn{9}{|l|}{ Transplant status } \\
\hline evaluated/waitlisted & 91 & 0.1 & 65 & $<0.001$ & 43 & 0.001 & 43 & 0.004 \\
\hline transplanted & 98 & & 93 & & 77 & & 73 & \\
\hline \multicolumn{9}{|l|}{ Insurance } \\
\hline public & 100 & 0.6 & 89 & 0.3 & 44 & $<0.001$ & 61 & 0.1 \\
\hline mixed or private & 98 & & 95 & & 82 & & 78 & \\
\hline \multicolumn{9}{|l|}{ Marital status } \\
\hline single & 96 & 0.3 & 100 & 0.2 & 57 & 0.01 & 52 & 0.02 \\
\hline married/partner & 99 & & 92 & & 81 & & 76 & \\
\hline \multicolumn{9}{|l|}{ Employment } \\
\hline full-time & 99 & 0.9 & 96 & 0.1 & 77 & 0.8 & 73 & 0.9 \\
\hline other & 99 & & 90 & & 78 & & 73 & \\
\hline \multicolumn{9}{|c|}{ Number of working adults in house } \\
\hline$\leq 1$ & 98 & 0.9 & 95 & 0.5 & 77 & 0.9 & 71 & 0.7 \\
\hline$>1$ & 99 & & 92 & & 77 & & 74 & \\
\hline \multicolumn{9}{|l|}{ Education } \\
\hline less than college degree & 100 & 0.9 & 92 & 0.7 & 78 & 0.9 & 67 & 0.3 \\
\hline college degree & 98 & & 94 & & 77 & & 75 & \\
\hline \multicolumn{9}{|l|}{ Race/ethnicity } \\
\hline Caucasian non-Hispanic & 99 & 0.9 & 94 & 0.2 & 77 & 0.7 & 75 & 0.2 \\
\hline other & 100 & & 86 & & 81 & & 62 & \\
\hline
\end{tabular}


Table 3: Trust in medical community

\begin{tabular}{|c|c|c|c|c|c|c|c|c|}
\hline & \multicolumn{2}{|c|}{$\begin{array}{c}\text { Trust medical } \\
\text { team }\end{array}$} & \multicolumn{2}{|c|}{$\begin{array}{l}\text { Agree with } \\
\text { medical team }\end{array}$} & \multicolumn{2}{|c|}{$\begin{array}{l}\text { Like medical } \\
\text { team }\end{array}$} & \multicolumn{2}{|c|}{$\begin{array}{c}\text { Team answered } \\
\text { questions }\end{array}$} \\
\hline & $\%$ & $P$ & $\%$ & $P$ & $\%$ & $P$ & $\%$ & $P$ \\
\hline Overall & 94 & -- & 93 & -- & 93 & -- & 94 & -- \\
\hline \multicolumn{9}{|l|}{ Insurance } \\
\hline public & 94 & 0.9 & 89 & 0.3 & 83 & 0.04 & 94 & 0.5 \\
\hline mixed or private & 95 & & 95 & & 97 & & 96 & \\
\hline \multicolumn{9}{|l|}{ Marital status } \\
\hline single & 100 & 0.6 & 100 & 0.4 & 100 & 0.4 & 100 & 0.4 \\
\hline married/partner & 94 & & 92 & & 93 & & 94 & \\
\hline \multicolumn{9}{|l|}{ Employment } \\
\hline full-time & 99 & 0.03 & 96 & 0.1 & 95 & 0.5 & 99 & 0.02 \\
\hline other & 91 & & 90 & & 92 & & 89 & \\
\hline \multicolumn{9}{|c|}{ Number of working adults in house } \\
\hline$\leq 1$ & 92 & 0.3 & 89 & 0.1 & 92 & 0.5 & 91 & 0.1 \\
\hline$>1$ & 97 & & 96 & & 95 & & 97 & \\
\hline \multicolumn{9}{|l|}{ Education } \\
\hline less than college degree & 89 & 0.1 & 89 & 0.3 & 92 & 0.7 & 94 & 0.9 \\
\hline college degree & 97 & & 94 & & 94 & & 94 & \\
\hline \multicolumn{9}{|l|}{ Race/ethnicity } \\
\hline Caucasian non-Hispanic & 95 & 0.9 & 93 & 0.6 & 93 & 0.9 & 95 & 0.3 \\
\hline other & 95 & & 90 & & 95 & & 90 & \\
\hline
\end{tabular}


Table 4: Provider communication about living-donor liver transplantation

\begin{tabular}{|c|c|c|c|c|c|c|c|c|}
\hline & \multicolumn{2}{|c|}{ Well-informed } & \multicolumn{2}{|c|}{$\begin{array}{l}\text { Complications } \\
\text { to recipient }\end{array}$} & \multicolumn{2}{|c|}{$\begin{array}{c}\text { Complications } \\
\text { to donor }\end{array}$} & \multicolumn{2}{|c|}{$\begin{array}{l}\text { Impact on } \\
\text { donor work }\end{array}$} \\
\hline & $\%$ & $P$ & $\%$ & $P$ & $\%$ & $P$ & $\%$ & $P$ \\
\hline \multicolumn{9}{|l|}{ Transplant status } \\
\hline evaluated/waitlisted & 43 & $<0.001$ & 75 & 0.3 & 75 & 0.9 & 69 & 0.5 \\
\hline public & 67 & 0.03 & 72 & 0.05 & 61 & 0.1 & 44 & 0.001 \\
\hline mixed or private & 87 & & 89 & & 79 & & 81 & \\
\hline \multicolumn{9}{|l|}{ Marital status } \\
\hline single & 74 & 0.1 & 91 & 0.7 & 70 & 0.4 & 74 & 0.9 \\
\hline other & 83 & & 82 & & 72 & & 71 & \\
\hline \multicolumn{9}{|c|}{ Number of working adults in house } \\
\hline$\leq 1$ & 85 & 0.7 & 87 & 0.7 & 77 & 0.8 & 75 & 0.9 \\
\hline$>1$ & 84 & & 85 & & 75 & & 74 & \\
\hline \multicolumn{9}{|l|}{ Education } \\
\hline less than college degree & 81 & 0.5 & 89 & 0.8 & 74 & 0.8 & 66 & 0.2 \\
\hline college degree & 85 & & 84 & & 76 & & 77 & \\
\hline \multicolumn{9}{|l|}{ Race/ethnicity } \\
\hline Caucasian non-Hispanic & 85 & 0.7 & 86 & 0.5 & 76 & 0.9 & 74 & 0.6 \\
\hline
\end{tabular}

